restrict the working of minerals should be extended to Local Authorities and Statutory Undertakings, which seems to be only right. It is to be hoped, however, that a more scientifically defined limitation in regard to the extent of lateral support to be left from subjacent minerals will be devised than that existing in respect of railways.

The exigencies of space prohibit a longer dissertation on this most valuable and interesting report, which is a model of conciseness and clarity, and should be widely and carefully read.

\title{
The Chemistry of Hormones.
}

THE British Associng the advantage over 1 a number of Decialist societies in that it brings togthemingstigators in different branches of science $Y$ it hakes good use of this advantage in the joint meetings of cognate sections and by discussions on the border line between two sciences. In framing his programme for the Leeds meeting, the recorder of Section B (Chemistry) must have had these advantages in view, for he secured contributions from a number of physiologists to a valuable discussion on Sept. 5 on the chemistry of hormones.

In opening the discussion, Prof. G. Barger (Edinburgh) began by explaining what is meant by a hormone. In contradistinction to the longknown method of stimulation by a nervous impulse, Bayliss and Starling first recognised, in the case of secretin, that a stimulus may also be brought about by a chemical messenger or hormone, set free in one organ and travelling through the blood stream to another organ which is then excited to activity. Thus the hormones are highly active and highly specific drugs which the body elaborates for its own uses. The preparation and study of the hormones is thereforc of the greatest importance to medicine, since they may produce effects quite unobtainable by the ordinary vegetable or synthetic drugs. The recent introduction of insulin in the treatment of diabetes is a case in point.

With the aid of lantern slides, Prof. Barger illustrated the course of development of our knowledge by reference to the two hormones which have so far been synthesised, adrenaline and thyroxine. There is first the recognition by the clinician or physiologist of the importance of the organ producing the hormone. In the two cases mentioned, this was followed by the discovery in it of some chemical peculiarity (chromogen in the adrenal gland, iodine in the thyroid). The biochemist then attempts the isolation of the active substance in a state of purity, and when this has been achieved, the organic chemist can investigate the molecular structure of the hormone and finally synthesise it; when the physiologist certifies the synthetic product to have the same degree of activity as the natural substance, some degree of finality has been reached.

For this reason Prof. Barger did not deal with the constitution and synthesis of adrenaline and thyroxine as choses jugees, but focussed attention on the crystalline substance of high molecular weight, obtained recently from commercial insulin by Abel and his co-workers, and having in a high degrec the physiological activity characteristic of this hormone. The substance can be recrystallised and retains its activity ; indeed, the residue loft on evaporation of the mother liquor is, weight for weight, much less active than the crystals. This would constitute a prima facie claim that insulin has thus been obtained in a state of chemical purity, but Abel, aware of the pitfalls which beset investigations of this kind, himself suggests the alternative, that the crystals may carry down "an unknown substance of almost unbelievable potency." The carrying down of insulin by a crystalline precipitate of a much simpler substance, benzoic acid, formed in its solution, has actually been used in the manufacture of insulin.

Prof. Barger directed attention to the analogous difficulty in appraising the recent work of Jansen and Donath, who described the isolation of the enormously active vitamin from rice polishings. These authors crystallised a hydrochloride from acetone and alcohol, converted it into the crystalline picrolonate and gold salt, and passed back from these to the original hydrochloride without loss of activity. Here adsorption would seem to be excluded. In the case of insulin the substance can only be crystallised from water in the same way as it is formed originally, i.e. by the careful addition of ammonia to a highly buffered solution.

The subsequent discussion showed that this method did not entirely satisfy organic chemists ; Prof. J. L. Simonsen compared it to the precipitation of barium sulphate; Prof. J. Mellanby pointed out the analogy to the crystallisation of proteins. A lettcr was read from Mr. F. H. Carr (unfortunately prevented from being present); he had carried out the crystallisation according to Abel's directions but found that the crystals were only one and a half times as active as the starting material (the ordinary commercial product of British Drug Houses, Ltd.). Others have also considered that the low potency of Abel's crystalline substance raises doubts as to its purity. This is, however, only an argument drawn from analogy; pure insulin may be less active than other hormones, and the only ways of settling the matter would seem to be, either to get the same crystals with a much smaller potency, or to synthesise them; the latter would be a formidable undertaking.

Prof. Barger ended by putting forward a theory of the action of adrenaline. and related amines, based on their adsorption by lecithin. He imagined the amino group of the hormone to be attracted by the phosphoric acid residue and the residual affinity of the acidic phenolic nucleus by the basic choline grouping; this would explain the optimal length of the side chain of two carbon atoms, the favourable effect of a phenolic hydroxyl, etc.

No. 3026, VoL. 120] 
Prof. H. S. Raper (Manchester) dealt next with the possible mode of formation of adrenaline in the organism. Although the organic chemist has disposed of adrenaline by synthesis, there is still work for the biochemist. Tyrosine appears to be the only possible precursor, and recently he has shown that this amino acid is actually changed by an animal oxidase to a catechol derivative, dihydroxy phenyl alanine. The latter is then converted to an indole derivative, which might, however, not occur if the amino group is substituted.

Prof. J. C. Drummond (London) referred to the enormous activity of irradiated ergosterol in preventing rickets. In his laboratory as little as 0.5-1 millionth of a milligram per day has lately been found sufficient for 100 grams of rat. The isolation of hormones is rendered difficult by a similar great potency. He referred to Abel's extremely active tartrate of a pituitary active principle, and to the fact that the same organ may produce several substances with different physiological actions. Similarly, the investigation of the ovarian hormone is complicated by the existence of a substance, ' anti-oestrin,' balancing the action of oestrin.

Prof. E. C. Dodds (London) discussed the ovarian hormone, which he has been unable to distil, as described for example by Fränkel and Herrmann; he doubts whether the active substance is really volatile. (The later experiments of Hartmann and Isler, who distilled the purified hormone after treatment with acetic anhydride, would seem, however, to leave little doubt on this point.) Prof. Dodds also questioned whether the ovarian hormone is a lipoid, and considered that it has a true solubility in water. He referred to experiments with solutions of adrenaline in oil, which retained some pressor activity after shaking with dilute hydrochloric acid. In any case the chemical purification of the ovarian hormone does not seem sufficiently far advanced to draw many conclusions as to its chemical nature.

Prof. J. Mellanby (London) described his experiments on the purification of secretin, which have resulted in an intensely active preparation, free from depressor substance. Contrary to Bayliss and Starling's view, that secretion is liberated from a 'pro-secretin' by acid hydrolysis, Prof. Mellanby considers that the substance is merely set free from an adsorption compound and in the normal process of digestion becomes fixed on bile acids. It is by adsorption on these acids that he has been able to effect so considerable a purification. Adsorption (on fuller's earth) is also the most effective preliminary stage in the purification of vitamin B. Although highly active, Prof. Mellanby's secretin is not yet chemically pure: one of its most significant properties is the absence of any reaction with ninhydrin.

In the general discussion, Dr. N. V. Sidgwick (the president of Section B), Prof. J. L. Simonsen, Dr. T. A. Henry, Mr. H. J. Channon, and others took part; Prof. G. Barger replied. It was generally felt that the discussion had been valuable in bringing chemists and physiologists together to consider debatable border-line problems on which their outlook is apt to differ with the nature of their studies.

\section{Prof. A. Liversidgesh.R.S.}

$\mathrm{T}$

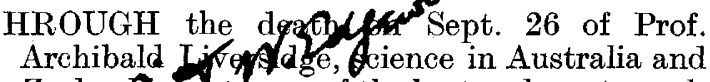
New Zealand hes lost one of the best and most unselfish of its ffinds. His death, due to heart trouble, in his eightieth year, came as a shock to his many friends, for even up to within a week or two of his decease he had always enjoyed robust health, and was exceptionally hale and hearty for his age. His nearest of kin surviving are his sister, Mrs. Balfern, of Buxted Lodge, Bexley, Kent, and his nephews Rear-Admiral E. Liversidge and Rear-Admiral J. G. Liversidge.

Born at Turnham Green in 1847, after studying at a private school and with tutors, Liversidge entered the Royal School of Mines and Royal College of Chemistry. Among his teachers were Frankland, Tyndall, and Ramsay. He gained an open scholarship in natural science at Christ's College, Cambridge, in 1867 ; and he was one of the two first students to work in Sir Michael Foster's physiological laboratory. After having been instructor in chemistry at the Royal School of Naval Architecture, he was appointed in 1870 demonstrator in chemistry at Cambridge. In 1873 he was elected to the chair of chemistry at the University of Sydney, a position which he held until

\section{tuary.}

1908. He at once threw himself whole-heartedly, and with singleness of purpose, into the scientific life of his newly adopted country. His great energy, meticulous method combined with a breadth of outlook, a shrewd financial acumen and a keen desire to serve science for its own sake, at once marked him as a coming organiser.

Liversidge originated the Faculty of Science at the University of Sydney in 1879, serving as its dean from that date until 1904, and the University School of Mines in 1890. Thanks to him also the Royal Society of New South Wales now owns a fine scientific library and a valuable building as its home. The first great impetus to technical education in New South Wales came largely from Liversidge, when a Member of the first Board of Technical Education at Sydney. As trustee of the Australian Museum, Sydney, from 1874 to 1908 he rendered invaluable service in helping to get together their fine collection, in greatly adding to their library, and in helping to secure for them their present fine building.

In 1885, Liversidge accomplished his greatest work in founding the Australasian Association for the Advancement of Science. Even those who know the relative isolation of scientific workers in Great Britain and Ireland previous to the founding of the

$$
\text { No. 3026, VoL. 120] }
$$

